\title{
HISTORIA DE UNA CRISIS: EL DIARIO DE MARIO GÓNGORA*
}

\author{
Leonidas Morales T. \\ Universidad de Chile \\ lmoralest@vtr.net
}

RESUMEN / ABSTRACT

El artículo aborda como objeto el Diario del historiador chileno Mario Góngora (1915-1985), $\mathrm{y}$, de manera específica, la modalidad de realización del género del diario íntimo que él ofrece. Según la hipótesis de lectura del artículo, esa modalidad de realización estaría definida por la presencia notoria en el Diario de Góngora de rasgos constitutivos de un género de la contabilidad mercantil propia de la tradición burguesa, el libro de cuentas, bajo cuya influencia justamente surge el diario como género moderno en la Europa del siglo XVII, pero que en Góngora parece ser un patrón actual y determinante. Las anotaciones del Diario aparecen así contaminadas con el sentido de una "cuenta" como contabilidad. Y lo que se cuenta día tras día en el Diario, es decir, el "capital" de Góngora, son lecturas interminables, infinitas, y, como precipitado de las lecturas, modelos de vida deseable (religiosa, política, matrimonial), pero que, asumidos biográficamente, acaban en fracaso. El Diario se cierra precisamente con una crisis general del sujeto. Siguiendo la línea de sentido del libro de cuenta, diría que el Diario termina con una "quiebra".

Palabras clave: diario, libro de cuentas, lecturas, crisis, género.

The article examines the Diario by Chilean historian Mario Góngora (1915-1985), and specifically, its mode of realization of the private diary as a genre. According to the reading hypothesis, this mode of realization is defined in the Diario by the remarkable presence of features associated to a genre of mercantile accountancy in the bourgeois tradition: the ledger. The diary arose as a modern genre in $17^{\text {th }}$-century Europe under the influence of this kind

Este ensayo fue escrito para el proyecto Fondecyt $\mathrm{N}^{\circ} 1110541$. 
of wrtiting. In Góngora this genre follows a pattern that is both dominant and consistent. The annotations in the Diario appear thus contaminated with the sense of a "record" as accountancy. And what is recorded day after day in the Diario, that is Góngora's "capital", are infinite, interminable readings and, amongst them, model lifestyles (religious, political, matrimonial). However, when these models are assumed biographically, they end up in failure. Actually, the Diario concludes with a generalized crisis of the subject. Following the order of a ledger, it can be said that the Diario finishes in a sort of "bankruptcy".

KEY WORDS: diary, ledger, readings, crisis, genre.

Mientras estudiaba Derecho en la Universidad Católica de Chile, Mario Góngora llevó un Diario de vida ${ }^{1}$. Lo había comenzado en 1934, a los 19 años. Las últimas anotaciones las escribirá a fines de 1937, 4 años después, a los 22 años. Cierra el Diario anunciando, desde una subjetividad manifiestamente agitada (trataré de proponer más adelante un sentido, no tan obvio, de esta agitación), su primer viaje a Europa para marzo del año siguiente, 1938. Todavía entonces, en América Latina, el "viaje a Europa" seguía siendo (conscientemente o no por parte del viajero) un ritual inaugurado en el siglo XIX, el siglo de la Europa de la revolución industrial y de la expansión neocolonialista. Prolongación de un ritual, o, lo que es igual, vigencia de su significado. El "viaje", en su repetición, se constituía cada vez en el gesto de un doble reconocimiento: el de la centralidad determinante de Europa dentro del desarrollo y la orientación histórica de las sociedades modernas ${ }^{2}, \mathrm{y}$, por lo tanto, el de la importancia de acceder a la "experiencia" de la vida cotidiana

1 La costumbre de llevar un diario había comenzado a extenderse, desde las primeras décadas del siglo XX, dentro de círculos intelectuales de sectores sociales medios y altos. En la década de 1930, un contemporáneo de Góngora, Alone, venía escribiendo un diario desde la década de 1910 (una mínima parte se publicó en 2001 por la Editorial Zig-Zag, en una edición de Fernando Bravo), mientras Luis Oyarzún, también contemporáneo, comenzaba a escribir el suyo (publicado en 1995 por el Departamento de Estudios Humanísticos de la Universidad de Chile, en una edición crítica de Leonidas Morales T.), junto con el de Alone los dos más extensos dentro de los publicados (cuando se publique el de José Donoso, tal vez pasará a ser el tercero).

Esta centralidad llegará a su fin con la Segunda Guerra Mundial, para comenzar a desplazarse poco a poco hacia Estados Unidos. El "viaje a Europa" pasará a ser finalmente el "viaje a Miami" o a "Nueva York". 
en las naciones desarrolladas del viejo continente como una clave cultural y política, tanto desde un punto de vista individual como social.

Góngora había terminado el año anterior (1936) los estudios de Derecho, y recibido de su Escuela el premio al alumno más destacado de su promoción. Sin embargo, no se sometió al resto de las exigencias formales para obtener el título profesional correspondiente, es decir, nunca se tituló de abogado. Lo cual tampoco constituye una sorpresa total para el lector del Diario: en anotaciones, de años diversos, declara su completo desinterés por las leyes. Estudia los sucesivos cursos de la carrera sin mayor entusiasmo, sin una verdadera identificación vital (existencialmente comprometida) con cada una de las problemáticas de esos cursos y su posterior función profesional, y solo como una rutina fatigosa derivada del asumir la decisión de haber ingresado a un lugar de profesionalización equivocado. De hecho, a la vuelta del viaje a Europa, comienza a estudiar Historia en el Instituto Pedagógico de la Universidad de Chile. En 1943 concluye sus estudios y en 1944 se titula de Profesor de Estado en Historia.

A lo largo de las cuatro décadas siguientes $(50,60,70$ y 80$)$, como resultado en parte de la docencia ejercida en la Universidad de Chile y en la Universidad Católica, pero sobre todo de la recepción crítica de sus libros $\mathrm{y}$ artículos publicados en torno a temas coloniales y del período moderno de la historia de Chile, el pensamiento de Góngora se constituirá en una propuesta imprescindible dentro de la historiografía contemporánea chilena y en un referente obligado para las nuevas investigaciones. Su libro Ensayo histórico sobre la noción de Estado en Chile en el siglo XIX y en el XX, tal vez sea, en términos de fundamentación teórica y profundidad de análisis, una de las reflexiones más sólidas (y además, agregaría, mejor escrita en un sentido literario, estético) sobre el período histórico que estudia, más allá de las controversias y reparos (muchos muy bien fundados) generados por algunas de sus tesis.

Ahora bien, transformar el pensamiento historiográfico de Góngora, tal como lo han fijando las sucesivas publicaciones, en un punto de partida metodológico para tender líneas de continuidad entre él y el Diario, no sería para nada una tentativa equivocada o improductiva. Las anotaciones juveniles del Diario podrían resultar particularmente iluminadoras desde el punto de vista de la genealogía de aspectos constitutivos, esenciales, del pensamiento de Góngora, especialmentede algunas tensiones (éticas) y opciones (sociales, culturales, políticas) que están en su base, tensiones y opciones que al mismo tiempo que contribuyen a fundarlo, alimentan su vitalidad. Pero no 
soy un historiador profesional como para intentar un rastreo semejante del pensamiento historiográfico de Góngora, remitiéndolo a las anotaciones del Diario (aunque la historia nunca pueda estar ausente de ninguna reflexión cultural). Lo que pretendo aquí es otra cosa: ofrecer una lectura del Diario de Góngora atendiendo solo a su condición genérica, es decir, a su específica condición discursiva de "diario de vida". Dentro de esta focalización, centraré la atención en ciertos signos, de diversa clase, tanto de la escritura como del soporte material de la escritura (luego diré cuál es éste y su importancia), que, leídos de una determinada manera, permiten reconocer en el Diario de Góngora una realización singular del género, con marcas formales que remiten a los orígenes históricos de éste, pero una realización por completo coherente en sí misma y cuyas características ponen a este Diario en un lugar aparte dentro de la historia del género, por lo pronto de su historia chilena.

A casi tres siglos y medio de sus orígenes europeos en el siglo XVII (si se toma el Diario de Samuel Pepys, llevado entre 1660 y 1669, como punto de partida, en Inglaterra), y a siglo y medio del comienzo de su reproducción en América Latina (el Diario de la escritora colombiana Soledad Acosta, con anotaciones entre 1853 y 1855, podría ser el primero), el lector actual de diarios íntimos no solo tiene frente a sí una cantidad monumental de realizaciones del género, producida principalmente en Europa y Estados Unidos (es sintomática su escasez en España y en América Latina). También tiene la sospecha, razonable por cierto, de que, en términos de modalidad de ejecución del género, no cabría esperar grandes sorpresas. Más allá desde luego del interés, siempre renovado, y siempre puntual, por los "secretos" de una nueva "subjetividad" (sobre todo si es la de alguien públicamente conocido) que la publicación de todo nuevo diario anuncia, y, en el terreno ya más propio del saber, del conocimiento, más allá asimismo del interés por las proyecciones literarias, históricas, biográficas, etc., de las anotaciones en cada diario particular.

Sin embargo, el Diario de Góngora, y a su manera, no confirma tales sospechas. En efecto, su lectura abre al lector a la experiencia de una modalidad de diario, primero, del todo inesperada, distinta a las conocidas en Chile, y segundo, incluso seductora como lenguaje y aventura intelectual, espiritual, psicológica, cuando se logra superar esa valla representada por el volumen de la carga erudita, a ratos agobiante, de sus anotaciones, lo que al comienzo bien podría desanimar a lectores impacientes. En las páginas que siguen trataré de describir la naturaleza de los elementos que parecen definir la modalidad de diario que hallamos en Góngora, y, luego, de mostrar cómo, 
dentro de esa modalidad, que es la de un discurso, se desarrolla una historia personal, la de un sujeto biográfico, Góngora, que poco a poco va entrando en el horizonte de una crisis de "transición", de "pasaje" (tomo esta palabra del lenguaje de los estudios del mito).

Para poder precisar cuál sea la modalidad de diario que tenemos en el caso del Diario de Góngora, me es necesario referirme a la materialidad de su escritura, al hecho de que comenzó en 1934 y terminó en 1937 como un manuscrito. Un texto escrito a mano sobre una superficie. Podemos llamar a esta superficie el "soporte" de la escritura. Ahora bien, lo que intento aquí es llamar la atención sobre este soporte y reparar en su identidad. Desde luego, cuando el proceso de la edición crítica del Diario ha concluido y el texto posteriormente publicado, la cuestión de la identidad del soporte desaparece para el lector institucional, no forma parte, como signo, del escenario de lectura al que se enfrenta. Pero aquí es indispensable restituirlo, en la medida en que contiene, a mi modo de ver, una clave de acceso a una dimensión principal de la modalidad de realización del género por parte de Góngora. Porque si bien el soporte ocupa una posición en general marginal, de contacto fronterizo con la escritura, desde esa posición, en el caso de Góngora, se convierte en un significante cuyo sentido es imposible ignorar en la lectura.

¿Concretamente, de qué se trata? De que Góngora fue escribiendo su Diario, con tinta negra, en las páginas lineadas de dos "cuadernos". Ambos de características similares y muy llamativas. En primer lugar, por su gran tamaño: de 29 centímetros de ancho por 39 de largo, y 4 centímetros de espesor, con más de doscientas páginas cada uno, y con gruesas tapas de cartón forradas en tela. En el interior de estos "cuadernos", las páginas del lado izquierdo van encabezadas por la palabra "Debe", y las del lado opuesto por la palabra "Haber", impresas las dos con caracteres tipográficos destacados. Se trata sin duda de los viejos libros de cuentas que la tradición burguesa europea consagró para el registro del movimiento de cifras de un negocio o actividad comercial.

Claro, el lector actual de diarios no espera que alguien lleve un diario de vida en libros de cuentas de dimensiones semejantes. Pero, poniendo un poco de humor, ¿por qué no escribir un diario en un libro de cuentas? No parece tampoco nada asombroso, excepto el tamaño y el peso, que hacían de estos cuadernos de Góngora objetos no concebidos (ni por sus fabricantes ni por sus compradores) para llevarlos en viajes, sino para tenerlos en un "domicilio" 
fijo (en la mesa de un escritorio, por ejemplo) ${ }^{3}$. Imposible representarse a Luis Oyarzún, el príncipe de los diaristas chilenos, conocido por su afición incurable a los viajes, a pie y en toda suerte de vehículos, y que acostumbraba escribir su Diario en los lugares por donde pasaba (los más imprevisibles), cargando consigo cuadernos semejantes. Sin extremar la oposición, y solo para sugerir un desvío, un contraste, de sentido no menor en una definición de ambos diaristas, cabría decir que el Diario de Oyarzún es el de un viajero, en tanto el de Góngora sería más bien el de un sedentario. Dos estilos diferentes de pensamiento. Dos modos de mirar y registrar el mundo.

Pero este particular soporte material de la escritura del Diario de Góngora de inmediato se inviste de connotaciones inesperadas tan pronto lo situamos en el contexto de la historia del diario en cuanto género moderno. Recordemos que la escritura del diario aparece, en el siglo XVII, como una práctica cultural burguesa. Es expresión de una nueva noción de "persona", dice Alain Girard (Girard 36-55). Las relaciones con Dios, con el mundo y consigo mismo propiciadas por la religiosidad de la Reforma y puestas en práctica dentro de los grupos protestantes, precipitan la conversión del yo en un "sujeto" autónomo, dueño de sí, de sus propios pensamientos y de sus actos, pero también individualmente responsable de los mismos, de su movimiento y sus efectos. En cuanto registro reflexivo y vigilante de lo que los días traen $\mathrm{y}$ dejan a su término, el diario se inscribe bien en el horizonte del nuevo sujeto burgués. Más aún: las anotaciones del diario son el equivalente, en el plano de la conciencia subjetiva, de las anotaciones del libro de cuentas en el plano externo de los negocios y actividades comerciales. Béatrice Didier, a propósito justamente del Diario de Samuel Pepys, un burgués inglés, sugiere la idea del libro de cuentas como el modelo originario del diario. Siguiendo el hilo de esta conexión, resulta seductor ver en las anotaciones del diario el "saldo" de los días, de lo ganado y lo perdido en cada uno de ellos. En otras palabras: del "Debe" y del "Haber. Incluso Didier lleva al extremo el paralelismo entre diario de vida y libro de cuentas: "Le journal n'est pas seulement un moyen de capitaliser: les souvenir, les jours, le moi; il est par lui même un capital; et un capital qui s'accroît à un rythme fort satisfaisant

\footnotetext{
Como no es imaginable que en sus frecuentes viajes a la costa, sobre todo Cartagena, llevara consigo estos "cuadernos", por su peso y tamaño, podemos suponer que las anotaciones del Diario correspondientes a esos momentos las haría en alguna agenda, o en un cuaderno escolar, para luego trasladarlas.
} 
pour peu que le diariste soit régulier: autant de jours perdus, autant de pages gagnées" (Béatrice Didier 49-55).

No sé si Góngora usó deliberadamente el libro de cuenta para escribir su Diario, consciente de su función histórica, es decir, la de una suerte de modelo originario del diario. Pudo perfectamente haber sido así. Y si no lo fue, entonces quedará como el azar de una alianza feliz entre el género de la escritura y las implicaciones histórico-culturales de su soporte material, físico. Pero ocurre que el azar de esta alianza (si fue un azar) no se cierra sobre sí mismo, sobre su propia ocurrencia, sino que tiene una proyección de sentido sobre la escritura del Diario. Una proyección tal, que convierte a esa particular conjunción de soporte y escritura en un portal: es la cifra que contiene la clave de la modalidad de escritura del Diario. En efecto, el Diario de Góngora nos sorprende con una forma, la suya, bastante insólita: pocos diarios, o tal vez ninguno, me atrevería a decir, se parece más como estructura, como formato de escritura, a un libro de cuentas, que el Diario de Góngora. Es esta forma, la semejanza que la define, la que caracteriza la modalidad de realización del género del diario que encontramos en el caso de Góngora.

Luego del reconocimiento anterior, una pregunta es inevitable: si el Diario de Góngora se nos ofrece, en la secuencia de sus anotaciones, como el ejercicio constante y estricto de una suerte de "contabilidad" de los días a la luz de una conciencia de sí y del mundo, ¿de qué "capital" (Didier) hace su reseña? En definitiva, ¿qué es lo que el día tras día le deja a Góngora para ser "contado"? No hay aquí lugar para la duda: la materia "contable" principal, la más evidente para el lector, la que registra con mayor acuciosidad, con una pasión soterrada, son, esencialmente, sus lecturas. Su "capital" son los libros. Pero este capital es al mismo tiempo una "inversión". ¿En qué? En algo más que un simple saber libresco. La lectura cumple funciones de sublimación, pero sobre todo es para él un ejercicio de exploración de signos de vida ejemplar en sus múltiples manifestaciones, que le permitan definir su ser en el mundo, construir en el tiempo su propia identidad.

Este joven chileno, hijo de padres separados, perteneciente a una familia católica de clase media, con recursos al menos suficientes para recibir una educación en colegio pagado y estudiar luego en una universidad privada, 
no sólo consigna en su Diario lo que va leyendo y lo que piensa de lo que lee, sino que junto con hacerlo también disemina frases de confesión que dejan a la vista, como un componente protagónico dentro de las condiciones subjetivas de la enunciación del Diario, un sentimiento de soledad persistente, biográfico, frente al cual la lectura se convierte en la puerta de acceso a un mundo alternativo (de ideas, imágenes, representaciones), desde donde la vida social y política, incluyendo la propia vida del diarista, finalmente parecen entregar de sí un sentido, volverse comprensibles, y hasta ofrecerse (la vida social y política) como escenario de proyectos de vida o de proyectos de acción.

Llama la atención, contrastando con el lugar totalizador ocupado por las lecturas y la riqueza de sus detalles, la pobreza sintomática con que se presenta en el Diario el contexto inmediato de la vida cotidiana del diarista, empezando por su vida familiar. Los espacios y los personajes del mundo familiar son presentados siempre en forma escueta, solo nombrados, donde los nombres son meras etiquetas de identificación: "mamá", "hermanas", "hermano", "casa", "balcón", como si unos y otros carecieran de interioridad o intimidad. Algo parecido ocurre con las referencias al espacio exterior: se reducen al empleo de términos más bien genéricos, como "el centro" (el centro de la ciudad), "la universidad" (donde estudia), "Castro", "Ejército", "las Agustinas" (calles de Santiago). No ocurre lo mismo, es cierto, cuando se trata de la naturaleza (árboles, cielos, aguas, la luz), la de las afueras de Santiago o la de la costa en el verano, que suele describir con un impulso fuertemente emotivo, desde una poética del entusiasmo, en una actitud contemplativa muy similar a la que suele adoptar en el amor, frente a la mujer (como lo veremos más adelante).

Es habitual, esperable además por parte del lector, una frecuente mención de libros y detalles de su lectura en el diario de escritores, artistas e intelectuales. Así ocurre, por ejemplo, en Chile, en los diarios de Alone (Hernán Díaz Arrieta), Luis Oyarzún, José Donoso. También desde luego en el de cualquier joven estudiante universitario abierto al mundo de la cultura y el pensamiento. Pero el caso de Góngora es simplemente insólito. No es que entre otras prácticas cotidianas acostumbre también leer: no, la lectura es en él una práctica diaria dominante, absorbente. Hasta tal punto, que al parecer para él la vida solo es pensable (y casi vivible) desde la lectura. Comienza su Diario el 8 de marzo de 1934, anotando la lectura del Tesoro de los humildes, de Maurice Maeterlinck, y del Primer amor, de Iván Turgueniev. De aquí en adelante son pocos los días reseñados en que no dé cuenta de lo que está leyendo, y las lecturas se acumulan, una tras otra, a veces de dos y 
más libros al mismo tiempo, en una sucesión a ratos vertiginosa. Leyendo así, él se suministra a sí mismo un antídoto contra el sentimiento de soledad, angustioso por momentos, a la vez que sostiene la construcción sin pausa de un orden interior de ideas y valores como coordenadas de su inserción en el mundo. Patricia Arancibia, que tuvo acceso al manuscrito del Diario de Góngora, hizo un listado de las obras leídas por el diarista cada año (Patricia Arancibia 281-324). El resultado fue: 153 libros en 1934, 268 en 1935, 200 en 1936, y 45 en 1937 (un año este último de anotaciones irregulares y, por razones examinadas más adelante, suspendidas abruptamente).

Son cantidades abrumadoras. Y cubren diversas esferas de la cultura y el pensamiento: literatura, arte, filosofía, lógica, historia, derecho, religión, testimonios de época. Además del francés, que parece dominar bien desde el comienzo, en el transcurso del Diario incorpora, aunque en citas mucho menos extensas, algunas solo una frase, el conocimiento de otras lenguas como el latín (en cuyo estudio se empeñó largo tiempo), el italiano y, hacia el final, también el inglés. Así sus vías idiomáticas de ingreso a la lectura se multiplican. Al principio del Diario solo se citan los títulos de los libros que va leyendo, y en general las anotaciones suelen ser bastante breves. Sin embargo, este patrón no dura. Ya en diciembre de 1934 comienza a producirse un cambio, con las lecturas justamente de Rilke y Dostoievsky, dos autores importantes para Góngora. Ahora se detendrá en lo que lee. Lo resume, lo comenta, lo enjuicia desde variados puntos de vista: estético, ético, religioso, y otros. A veces, el registro de los pormenores de una determinada lectura se prolonga por más de un día, en una concentración total del tiempo del Diario, con exclusión de cualquier otra circunstancia de la cotidianeidad.

Repito: no son éstas en absoluto lecturas animadas por una pura curiosidad erudita. Por el contrario, son la expresión intensa, apasionada, de un sujeto que busca en los libros las huellas, los signos, los indicios de un modelo de vida, de un modelo de existencia en el cual reconocerse, desde el cual pensarse y pensar su momento histórico. Un modelo que también incluye una "tonalidad" del sentimiento (estético o ético) capaz de identificarlo. Son múltiples y diversas las lecturas decisivas en este sentido, y por ellas pasa, sin duda, la formación del sustrato de lo que será posteriormente el pensamiento historiográfico de Góngora. ¿Qué lecturas son éstas? Los libros de la Biblia, el Dante, Pascal, Santa Teresa, San Juan, Quevedo, Spinoza, Dostoievsky, el historiador Ernest Lavisse. Y entre sus contemporáneos: Maritaine, Spengler, Gide, Rilke. A ello hay que sumar, e integrar al mismo sustrato, otras experiencias culturales de registro igualmente reiterado, como la de la 
música y la pintura. Dedica una y otra vez páginas del Diario al comentario de numerosos pintores, de diferentes épocas, aunque siempre vuelve a aquellos que para él son ejemplares, como el Giotto, por el sentido religioso y, sobre todo, Rembrandt, por su maestría para marcar la temporalidad en los rostros y las figuras humanas. Espacio similar ocupa en el Diario la música, y también aquí retornan las referencias a las ejemplaridades, entre ellas, y en primer lugar, la música de Bach.

Si ya en sí misma resulta inaudita esta dedicación tan extrema y tan obstinada a la lectura en un joven de 19, 20, 21 o 22 años, y en varias lenguas, sobre temas, géneros discursivos y disciplinas diversos, dedicación extendida a la pintura y la música, la sorpresa es aún mayor cuando reparamos en el lenguaje de las anotaciones del Diario. Se trate de literatura, filosofía, historia, pintura o música, el joven diarista demuestra siempre suficiente competencia técnica (en el manejo de la especificidad de los discursos respectivos, de sus términos y conceptos constitutivos), y talento en la construcción de la frase, una frase tributaria de la exactitud, construida con las palabras necesarias,entregada a una estética de lo esencial, sin retorcimientos ni aspavientos ${ }^{4}$. Es una prosa que en este sentido anuncia la de su libro tal vez más importante, Ensayo histórico sobre la noción de Estado en Chile en el siglo XIX y el XX. Más aún: en algunas anotaciones del año 1937, como en la última justamente de ese año, que es también la última del Diario, y en un contexto de crisis personal, de fractura de la emotividad (hablaré de esto más adelante), irrumpe un lenguaje con momentos de gran vitalidad, de gran fuerza expresiva, un lenguaje poético en la verdad humana que por sí mismo y dentro de sí a la vez instala y abre.

Ese modelo de vida o de existencia que Góngora rastrea en lo que lee, o en lo que impresiona su sensibilidad desde el sonido de la música o el color de la pintura, es ante todo cristiano, católico. No cesa de apelar a los libros de la Biblia, al testimonio de los apóstoles, a figuras de la historia de la Iglesia (San Francisco) o a la escritura de los místicos (Santa Teresa, San Juan), para fundamentar principios de visión de vida humana, de comprensión de destinos, de afirmación de la trascendencia del ser del hombre, de la mediación de Cristo en todo camino cierto. El "amor de Cristo", la "gracia" divina, la "caridad", son palabras repetidas en el Diario, y a su sentido el diarista se encomienda.

4 Hay sí algunos casos en que parece relajarse la atención del diarista y como consecuencia resultan frases de trabazón lógica débil e incluso fragmentada. 
Su cristianismo en todo caso mantiene una relación crítica con el cristianismo tradicional, establecido,"institucionalizado". Como muchos otros en las décadas de 1920 y 1930, en Europa y América, enfrentados a lo que ellos pensaban como una doble "amenaza" a toda concepción cristiana de la vida, la amenaza del capitalismo y la del comunismo, Góngora (como Gabriela Mistral) lucha por "revolucionar" el cristianismo católico, volviendo a sus raíces, confiado en su capacidad para responder a los problemas sociales del presente, y, paralelamente, para orientar (bajo la forma de la imitatio) la construcción de un proyecto de vida personal. ¿Qué consigna el Diario de esta lucha? ¿Cuál fue, según el Diario, el resultado de la puesta en juego, a la vez social y biográfica, hecha por Góngora, del modelo cristiano intuido o verificado en sus infinitas lecturas, en sus momentos de plenitud como oyente de la música, como espectador de la pintura del mundo occidental? El fracaso acompaña al empeño por llevar el modelo al cumplimiento de su promesa, en cada uno de los planos en que se lo intenta. Hay uno de estos planos que me interesa vivamente por la universalidad de lo que ahí está en juego. Será el tema central del último apartado de mi ensayo.

Es oportuno llamar la atención aquí, a manera de introducción, sobre un detalle significante del modo con que se presenta en Góngora la "contabilidad" de los días. Todos los que se han ocupado de la teoría del diario íntimo (Alain Girard, Béatrice Didier, Maurice Blanchot, Philippe Lejeune), diferenciándolo a la vez de otros géneros vecinos (memorias, autobiografías, cartas), destacan como una de sus propiedades esenciales el que la escritura se da en él siguiendo el orden de los días, dejando constancia del día y lugar de la enunciación. Blanchot resumía esta obligada relación de servidumbre con la sucesión de los días, diciendo que el diario es un esclavo del calendario, está sometido a él (Maurice Blanchot 207). Ninguno pensaba desde luego que el diarista debiera escribir "todos" los días. Efectivamente, el diarista respeta la subordinación al orden de los días, pero con alguna libertad: no solo no escribe necesariamente todos los días, sino que incluso pueden darse en la sucesión de las anotaciones, ocasionalmente, silencios de varios días, o más, de los que el diario se hace cargo a veces con una explicación. Góngora nos pone ante un modo absoluto de ceñirse al calendario: escribe su Diario prácticamente todos los días. Solo en el último año, 1937, que coincide, como dije, con un período de crisis, se 
rompe esta regla. En general escribe pues casi todos los días de la semana, y cada día, sin nombrarlo, lo identifica por su número en el calendario, con un número árabe, y el número de cada mes, con un número romano. Pero el día domingo, invariablemente, como cumpliendo con un ritual de escritura, lo encabezasiempre con su letra inicial: "D".

Escribir el diario todos los días, sin excepciones significativas, durante cuatro años: ¿cómo comprender esta práctica tan empecinadamente regular, como ensimismada, de un joven estudiante universitario? Siendo para él la lectura la actividad principal del día, de todos los días, comentar en el Diario las tesis de un filósofo, las peripecias de una tragedia o de una novela, el pensamiento de un historiador, determinados pasajes de los Evangelios, etc., podría perfectamente funcionar como un método, consciente o no, para retener (mejor que la memoria) lo sustancial de lo que se lee, o para procesar discriminadamente (críticamente) las lecturas. Aun cuando sea así, y de hecho es así también, hay en ese seguir atento el retorno de los días para volver, sumiso, a anotar en el Diario la constancia de su paso, de lo que dejaron al final de cada uno, un más de significado que pareciera apuntar en otra dirección. El retomar cada día las anotaciones del Diario, constituye claramente la expresión del sometimiento a una disciplina. Pero no a una disciplina cualquiera. Es expresión de una disciplina que a su vez evoca otra. Evoca, por un lado, la disciplina con que el burgués lleva su libro de cuentas. Por otro, y más directamente, apunta en la dirección del sentido religioso que, obstinado, Góngora busca para su vida, y en este plano, evoca la disciplina de los monjes de claustro, que repiten cada día acciones y oraciones, para dar gracias, para vencerse y ganarse.

Pero este "monje" laico, Góngora, aun cuando la soledad lo rodea y sus lecturas parecieran hechas en el apartamiento y el silencio de alguna biblioteca conventual, no vive en un claustro: su concepción religiosa del hombre y del mundo (una religiosidad actualizada, renovada, adecuada para él a los nuevos tiempos), tendrá que ponerse a prueba dentro de la sociedad concreta, histórica, en la que vive, la de Chile en la década de 1930, sin rehuir sus desafíos. Y lo hará, pero a su manera: siempre vacilante en sus decisiones, oscilando entre la atracción por una vida dedicada a Cristo, de un lado, y, de otro, su sensibilidad frente a los intereses del mundo, como la política o el deseo de formar una familia.

En 1934 entra al Partido Conservador y, dentro de él, a la Asociación Nacional de Estudiantes Católicos (Anec), de la que llegará a ser vicepresidente. Escribe, sin extenderse (sin demasiado entusiasmo) sobre su participación 
política, sobre algún discurso suyo recepcionado con éxito por la audiencia, o sobre alguna marcha partidaria. Fue también director de la revista Lircay, publicada entre 1934 y 1938. Una revista de pensamiento político asociado al de los jóvenes conservadores y a su proyecto de convertir la renovada doctrina social de la Iglesia (expuesta en la encíclica reciente de Pío XI, Quadragésimo Anno, del 15 de mayo de 1931) en la base de su acción política. (Algunos de estos jóvenes conservadores harán de ese proyecto el fundamento ideológico de un nuevo partido político, la Democracia Cristiana) ${ }^{5}$. El pensamiento político de Góngora, su conservadurismo católico, determina, por supuesto, sus simpatías y diferencias frente a los acontecimientos políticos de la Europa de esos años. Aunque circunstancialmente, en 1934 (anotación del 30 de marzo), a raíz de la lectura de un artículo, reconocía en su Diario "cierta inclinación al fascismo". Como también reconocerá, paralelamente, su rechazo al comunismo y al ateísmo de su doctrina. El levantamiento de Franco en España, que da comienzo a la guerra civil (1936-1939), lo celebra con un "por fin" (19 de julio, 1936), y seguirá con atención en los periódicos la primera fase de los acontecimientos políticos y militares de la península.

"Quisiera luchar", dice Góngora (23 de diciembre, 1935). Pero su disposición aparece frenada, cuestionada en su raíz, por impulsos en dirección contraria. Uno de estos impulsos lo lleva a pensar, una y otra vez, en el abandono de la acción política para dedicarse solo a Cristo, a su servicio, como la única vía de una realización plena. En el mes de enero de 1935 (anotaciones del 15 y el 30) reflexiona sobre el camino del sacerdocio, al que se siente "inclinado", confiesa. Habla y discute con sacerdotes de confianza sus planes. Cuando se los comunica a su madre, la reacción de ésta, al comienzo, fue de oposición, de resistencia a semejante proyecto del hijo. Pero ya en febrero de ese mismo año 1935 (consigna una anotación del día 18) ella termina aceptando, o conformándose. Finalmente, ya sabemos, ni la vía política ni la del sacerdocio fructificaron. Fueron, de alguna manera, fracasos.

Hay todavía otro escenario donde Góngora pone a prueba su modelo de vida cristiana. Y no es uno más. Es nada menos que aquel en que aparece comprometido como sujeto de deseo sexual. Entra pues en el escenario la mujer. A primera vista, las referencias a la mujer y al amor cubren un espacio muy menor dentro del conjunto de las anotaciones. A menudo no son más de 
una o dos frases en una anotación del día de una o más páginas. Sin embargo, esa posición aparentemente de segundo plano en las anotaciones del Diario no guarda relación con la importancia que tienen, tanto desde el punto de vista de la sexualidad misma de Góngora, como de los efectos del desenlace final de las peripecias de esta sexualidad sobre toda la armazón espiritual, psicológica, intelectual del diarista.

Si las referencias a la mujer y al amor no llaman la atención por su extensión, en cambio sus contenidos, las relaciones entre éstos y su distribución en el tiempo (abren y cierran el Diario, y lo van pauteando, a la manera de un contrapunto, a lo largo de todos su desarrollo), constituyen elementos de un verdadero proceso psicológico y ético, cuyo sentido desempeña un papel central en el juego de los diversos significados de las anotaciones del Diario. Este proceso va articulándose en escenas o fragmentos de escenas. Por algunos detalles de las escenificaciones, el proceso asume connotaciones marcadamente "teatrales", de "drama", donde no faltan ingredientes propios de la comedia. La recurrencia del fantasma del "pecado", asociado al fantasma paralelo de lo "carnal", trae a la memoria las representaciones medievales, los auto-sacramentales, por ejemplo. Pero el proceso también podría definirse como una dramatización con nudos temáticos obviamente "psicoanalíticos". En las relaciones del diarista con la mujer saltan a la vista tópicos constitutivos del relato del psicoanálisis: el objeto del deseo, la represión, el retorno de lo reprimido.

El movimiento del proceso en que Góngora se pone en juego como sujeto de deseo sexual aparece dividido en tres momentos sucesivos (iba a decir en tres "actos"...). Estos tres momentos coinciden en su sucesión con la secuencia de los años:1934, 1935 y 1936. El último año del Diario, 1937, presenta todas las características de un "epílogo", con el desenlace de las tensiones acumuladas y no resueltas. Cada momento incluye, como objeto del deseo, una muchacha distinta. La figura del primer momento es Inés. No deja de ser además revelador del lugar que ocupan la mujer y el amor como nivel de condensación y articulación de un sentido que compromete a la totalidad del Diario, el hecho de que la primera anotación del Diario, muy breve, sea compartida por la mujer y los libros: comienza con el nombre de Inés y sigue con las primeras lecturas registradas. La referencia a Inés dice: "Intento indecible de sentir cariño verdadero por Inés Fleischmann. La he visto: ha sonreído" (8 de marzo, 1934). Extraña manera de presentar el amor: "Intento indecible de sentir cariño verdadero". ¿No está enamorado? ¿Solo quiere llegar a estarlo, a "sentir cariño verdadero"? Este rasgo voluntarista, 
del amor como un querer enamorarse, no está del todo ausente en las demás relaciones amorosas del diarista.

En las anotaciones de ese año 1934, el nombre de Inés es reiterativo. Pero el lector nunca ve un encuentro, confesiones directas, aceptación y contacto físico, de cuerpos. La mujer, el objeto del deseo, aparece siempre en la distancia: como un objeto del deseo más bien contemplado, o como el objeto del deseo cuya esfera el sujeto ronda, sin romper la distancia. A veces el acercamiento se resuelve en un juego de rasgos infantiles. Por ejemplo, Góngora de pronto sigue a Inés y sube al tranvía en que ella va. La mira, la escudriña, atento sobre todo a si ella lo mira a él, como si ella tuviera que conquistarlo a él. El juego no es inocuo: desde la distancia Inés le despierta deseos carnales. Sin embargo, no la aborda, no le confiesa sus sentimientos, a pesar de que, por la información indirecta del Diario, el lector infiere que se conocen. Esta retención es claramente una auto-represión. Se justifica diciendo de sí mismo que es "feo", que no tiene méritos de ningún tipo para conquistarla. Pero como no cesa en su deseo, opta por apelar a una mediación "celestinesca", la de la Providencia, para que ella le entregue a Inés: "No tengo ninguna confianza en mis medios, no tengo ni la figura exterior ni la calidad interior del conquistador. Sólo espero en algo que venga de arriba" (28 de septiembre, 1934).

Y, claro, "de arriba" nada vino. Además, el sentimiento amoroso debía también disputar sus dominios y sus pretensiones con los pensamientos que no descartaban la opción del sacerdocio, especialmente fuertes ese año 1934. Los primeros meses del año siguiente, entre enero y marzo, Inés se pierde, desaparece del campo del deseo del diarista, con la misma arbitrariedad con la que entró (un poco a la manera de esas otras historias, también voluntaristas, las de las novelas de caballerías). En su lugar, entra Silvia, que ocupa menos espacio y tiempo en el diario: solo abril y mayo de 1935. La última será Elena Pinto Stevenson: desde octubre del 35 a abril del 36. Son todas muchachas de comportamientos previsibles, es decir, que se mueven dentro de los códigos sociales y éticos establecidos. Ninguna por lo tanto en condiciones de responder a la subjetivización extrema de los códigos del joven Góngora. Códigos éstos que incluso invierten los roles socialmente asignados a hombres y mujeres, dándole al hombre el de la iniciativa y a la mujer más bien el de la reactividad.

El 16 de abril de 1936, Góngora se declara "derrotado". Un curioso derrotado en una batalla que nunca se dio. Con algunas variaciones, se repite el modo básico de la relación del diarista con las tres muchachas: ellas son 
siempre el objeto de una contemplación amorosa, definida cada vez por el efecto de distancia o de lejanía. Es de ellas de quien se espera sin embargo el gesto, inspirado por la Providencia, que romperá la distancia en una milagrosa manifestación de atracción y voluntad de compromiso. Como tal gesto providencial nunca se produce, la distancia inhibe el contacto físico entre ellos, el erotismo de los cuerpos. Mientras, el diarista, en este contexto, se niega a sí mismo, se reprime, dice no tener condiciones de amante y vuelve a depositar su suerte en las manos de la Providencia y a reafirmar su fe en el matrimonio como el verdadero lugar donde el amor cristiano se realiza y se proyecta en los hijos. En una oportunidad, como agotado por los juegos amorosos improductivos con las tres muchachas, hace suyo el imaginario burgués, pero lo hace de manera irónica, reduciendo la riqueza y complejidad del amor a un refinado bien de consumo dentro de una serie: todo debería terminar, escribe, con "un buen amor, un viaje a Europa, una cultura exquisita"... (26 de julio, 1936).

A la sombra de las lecturas, la vida interior de Góngora, una de lúcida soledad, de pensamientos y sentimientos incomodados por las dudas, las deserciones repetidas (de la carrera de abogado, de la participación política, de la opción del sacerdocio), los amores fantasmagóricos, sublimaciones del amor auténtico, simulacros al final, está simultáneamente recorrida por los indicios de una energía sexual reprimida, subterránea, pero persistente en su presión sobre la sensibilidad y la conciencia. Los indicios asoman a la conciencia cristiana del diarista asociados al "pecado". Poco a poco van haciéndose más ostensibles, más insistentes y apelativos. Ya el 4 de junio del año 1936 habla abiertamente de "angustia sexual". Y el 4 de diciembre de ese mismo año inicia una anotación escribiéndola en francés, usando esta lengua como una máscara idiomática para expresar lo que en español le hubiese resultado a lo mejor demasiado fuerte ${ }^{6}$. Y lo que registra no es más que el estado de una conciencia sexual sobreexcitada, de extrema alteración. Las anotaciones de 1937, el epílogo de esta suerte de "representación" dramática, hacen visible el quiebre final de la resistencia, la ruptura de los muros de contención, es

\footnotetext{
El párrafo: "Hier soir fut l'une des nuits plus horribles de ma vie. J'étais agité et excité. Je sortis. Alors, le désir... Désir inutile et lâche, qui tient plus à la satisfaction dans l'image, par peur de ce lumineux et inmonde mystère. Désir qui laisse une amertume mortelle. Je me suis mépris moi même, moi même pauvre homme, pauvre diable enchaîné par la luxure la plus banale. La solution? Une sexualité pure, humaine, pas animale, vivante. Mais, comment?"
} 
decir, el triunfo del "pecado" a través de la satisfacción sexual. "He pecado", dice el 10 de junio de 1937. El 29 de noviembre es mucho más explícito: "Mi primera unión, la primera en la que no sólo tuve goce de la mujer, sino en que se lo doy". Es imposible pensar en Inés, Silvia o Elena. Es probable que haya sido una prostituta.

El Diario termina con el ingreso del diarista en un estado de "crisis": se han roto previsiones, han naufragado proyectos, y el sujeto queda un poco a la intemperie desde el punto de vista de las coordenadas de orientación de su vida. Siguiendo las líneas de sentido de la propuesta según la cual podíamos reconocer en la modalidad de realización del género que ofrece Góngora, el formato del "libro de cuentas", también cabría decir, jugando con las analogías, que el Diario de Góngora llega a su fin con el registro de una "quiebra".

Si bien el Diario se interrumpe aquí, y no se ocupa de qué sucedió después del viaje a Europa que anuncia para los meses próximos, de cómo fueron los términos de su recomposición del cuadro de su existencia, de su pensamiento social, político, historiográfico, sí tenemos, en la última anotación del Diario, una clara señal de que, en el tránsito de la crisis y gracias a ella, el sujeto se ha abierto a una percepción más rica, más verdadera también, de la realidad, ya no sometida a condicionamientos que ocultan o distorsionan el hecho simple, y definitivo, de que el hombre vive en el tiempo y no tiene más que el tiempo que vive. Ya, en la anotación del 29 de noviembre, después de consignar su "primera" vez, agregaba: "Empiezo a comprender el fervor y la paz de la unidad carnal". Pero ahora, al escribir su Diario por "última vez", su conciencia del tránsito es mucho mayor. Vale la pena citar más extensamente esta anotación, escrita, consigna el diarista, en la "Madrugada del martes 21 de diciembre", como si, consciente de la experiencia crucial que vive, debiera dejar constancia del exacto momento en que la enuncia. El tono es febril, y el lenguaje, de una sobriedad poética:

"Escribo en mi Diario, tal vez por última vez. En diez días más estaré en Cartagena y a fines de marzo me iré a Francia. Estoy ya decidido a arrojar lejos mi pasado y llegar iadónde? Irse, único modo de llegar. La primera noche del último verano que paso en Chile, estoy melancólicamente resignado. La noche es hermosa. Llegan aquí, a mi ventana, sólo algunos ladridos de perro y la gran luz de la luna. Y mi cuerpo solo, solo ante todo, solo ante su destino, frente al inmenso silencio y a la inmensa interrogación exterior. ¿Qué será de mí? No sé. Todas las ideas, todos los planes, todas las teorías han caído y quiero 
solamente entregarme al viento que pasa, encontrar en él una respuesta, viva y fresca. ¿Mi moral? Ya no me reprimo en cuanto al sexo. No lo haré. Veo que una lucha moral enderezada contra los propios defectos es estéril y negativa. Tal vez no procure ya más hacer tal cosa, sino optar por dejar avanzar mis defectos y cultivar mis cualidades. Quiero una actitud más positiva y creadora, aunque sea menos santa. Ser bueno, humanamente bueno. ¿Mi fe? Decaída, tibia (...). Además conservo viva la facultad de integrarme cuando veo la fe de Cristo corrompida y traicionada por la Iglesia al hacerla un partido de lucha religiosa, de "guerra santa", al identificarla con el franquismo (...). He peleado con todo el derechismo, mi revolucionarismo será cada día más fuerte. ¿Amistad, amor? Nulos. Todos los días converso con Tejeda, Wendt, Sanhueza, Scarpa, Undurraga, o escribo a Tomic. Y sin embargo... ¿Qué es la vida, dónde cogerla".

\section{BIBLIOGRAFÍA}

Arancibia, Patricia. Mario Góngora en busca de sí mismo (1915-1946). Santiago: Fundación Mario Góngora, 1995.

Blanchot, Maurice. "El diario íntimo y el relato". En El libro que vendrá. Caracas: Monte Ávila Editores, 1992.

Didier, Béatrice. Le journal intime. Paris: Presses Universitaires de France, 1976.

Girard, Alain. Le journal intime. Paris: Presses Universitaires de France, 1963.

Góngora, Mario. Ensayo histórico sobre la noción de Estado en Chile en los siglos XIX X XX. Santiago: Editorial Universitaria, 1986.

Pereira, Teresa. "Lircay (1934-1938): Una expresión política-doctrinaria del joven Mario Góngora”. En AA.VV., Reflexiones sobre historia, politica y religión. Homenaje a Mario Góngora. Santiago: Ediciones Universidad Católica de Chile, 1988. 